\title{
Racing to the Rubicon
}

\author{
Michael J. Reardon, MD, ${ }^{a}$ and Vinod H. Thourani, MD $^{\mathrm{b}}$
}

\footnotetext{
From the ${ }^{\mathrm{a} D e p a r t m e n t}$ of Cardiovascular Surgery, Houston Methodist DeBakey Heart \& Vascular Center, Houston, Tex; and the ${ }^{\mathrm{b}}$ Department of Cardiac Surgery, Medstar Washington Hospital Center/Georgetown University, Washington, DC.

Disclosures: M.J.R. reports advisory board work for Medtronic and Boston Scientific. V.T. has nothing to disclose with regard to commercial support.

Received for publication July 25, 2017; accepted for publication July 31, 2017; available ahead of print Sept 6, 2017.

Address for reprints: Michael J. Reardon, MD, Department of Cardiovascular Surgery, Houston Methodist DeBakey Heart \& Vascular Center, 6550 Fannin, Suite 1401, Houston, TX 77030 (E-mail: mreardon@ houstonmethodist.org).

J Thorac Cardiovasc Surg 2018;155:1457-8

$0022-5223 / \$ 36.00$

Copyright (c) 2017 by The American Association for Thoracic Surgery

http://dx.doi.org/10.1016/j.jtcvs.2017.07.055
}

In this issue of the Journal, Maximus and colleagues ${ }^{1}$ report on a study in which they examined the growth of transcatheter aortic valve replacement (TAVR) and its relationship to surgical aortic valve replacement (SAVR) volumes in California from 2009 to 2014. TAVR increased dramatically, whereas SAVR showed an increase for the first 3 years and then a slight decrease in year 4. Maximus and colleagues ${ }^{1}$ conclusion was that the increase in SAVR volumes despite increasing TAVR volumes may have been caused by inclusion of high-risk patients who were not previously presented with the option for surgery. These are interesting data, with the question remaining, "What does this mean for cardiac surgeons?"

Commercial approval was available only for extreme and high surgical risk TAVR cases during this study. Since that time, Food and Drug Administration approval for the use of TAVR has been expanded to include intermediate-risk patients, and 2 randomized low-risk research trials are currently enrolling. This study showed an early increase in surgical volume, with a slight fall in the final year. At our own institutions, we have seen the same pattern, with an early increase in SAVR followed by a subsequent decrease in surgical therapy. With the dramatic increase in TAVR, however, we have seen an overall increase in total aortic valve procedures. With the apparent risk creep that seems to be prevalent and with intermediate-risk use now commercially approved, will all patients with symptomatic severe aortic stenosis get TAVR? If TAVR is noninferior in the low-risk trials, will this lead to low-risk approval and will all low-risk patients then get TAVR? Will this mark the beginning of the end for cardiac surgeons?

We believe that the answer to all these questions in a resounding no. We agree that the increase in SAVR after the introduction of TAVR is largely driven by patients who previously were not even given the chance to discuss treatment options with a qualified surgeon and now see the valve team and hence the surgeon for this conversation. We believe that as we move down the risk scale, this number

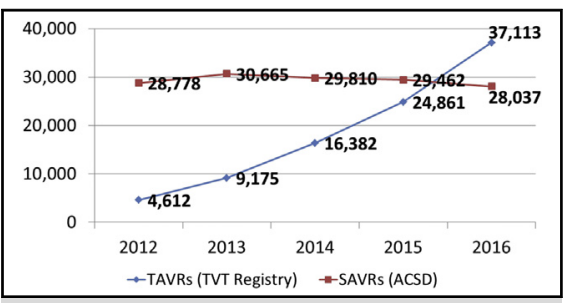

Isolated surgical AVR versus transcatheter AVR in the United States. Based on Transcatheter Valve Therapy Registry and Society of Thoracic Surgeons Adult Cardiac Surgery Database US data sets.

\section{Central Message}

Transcatheter aortic valve replacement now exceeds isolated surgical aortic valve replacement in the US, and this trend will not reverse course. Cardiac surgeons should become expert in the procedure.

See Article page 1447.

of previously unconsidered patients may decrease; however, the number remains substantial. Further, there are patients who remain better candidates for surgery because of anatomy. Bicuspid valves with or without aortopathy were excluded from all the US randomized trials, and excessive left ventricular outflow tract calcification is still easier to address surgically. Other scenarios include those young patients who wish to have a mechanical prosthesis or those with significant concomitant cardiac disease. Surgery for aortic valve disease will not go away, but cardiac surgeons must have a clear view of the future.

The last quarter of 2016 saw for the first time the volume of TAVR exceed the volume of isolated SAVR, as noted in the Transcatheter Valve Therapy Registry and Society of Thoracic Surgeons Adult Cardiac Surgery Database US

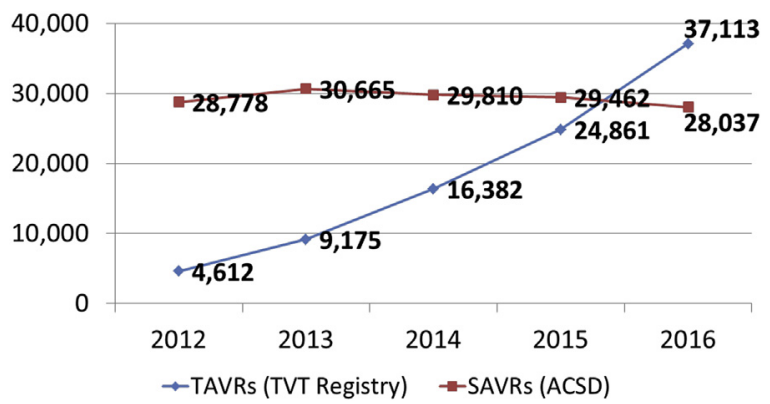

FIGURE 1. Isolated surgical aortic valve replacement procedures $(S A V R s)$ versus transcatheter aortic valve replacement procedures (TAVRs) in the United States, 2014 through 2016. TVT, Transcatheter Valve Therapy; $A C S D$, Adult Cardiac Surgery Database. 
data sets (Figure 1). With the commercial approval of TAVR for intermediate-risk patients, we do not believe that this pattern will reverse. Just as vascular surgeons embraced catheter skills with the introduction of the transcatheter treatment of abdominal aortic aneurysms, cardiac surgeons should embrace the same for TAVR. When Julius Caesar crossed the Rubicon on his march to Rome, he is purported to have said, "The die has been cast," noting that there was no turning back. Whether we are racing to the Rubicon or it is already in our rearview mirror, there is no turning back for cardiac surgeons. Programs that embrace TAVR and surgeons who become expert in this procedure will thrive; those that do not will likely go the way of Caesar's Roman senate.

\section{Reference}

1. Maximus S, Milliken JC, Danielsen B, Shemin R, Khan J, Carey JS. Implementation of transcatheter aortic valve replacement in California: influence on aortic valve surgery. J Thorac Cardiovasc Surg. 2018;155:1447-56. 